\title{
Depressive Symptoms in Newly Diagnosed Lung Carcinoma: Prevalence and Associated Risk Factors
}

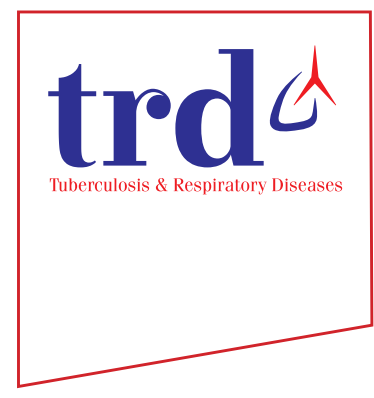

\author{
K. K. Shahedah, M.Med. ${ }^{1}{ }^{(\mathbb{D}}$, S. H. How, M.Med. ${ }^{1}$, A. R. Jamalludin, M.P.H. ${ }^{2}$, M. T. Mohd Faiz, \\ M.Med. ${ }^{3}$, Y. C. Kuan, M.R.C.P. ${ }^{1}$ and C. K. Ong, M.R.C.P. ${ }^{4}$ \\ Departments of ${ }^{1}$ Internal Medicine, ${ }^{2}$ Community Medicine, and ${ }^{3}$ Psychiatry, Kulliyyah of Medicine, International Islamic \\ University Malaysia (IIUM), Kuantan, ${ }^{4}$ Department of Respiratory Medicine, Penang General Hospital, George Town, Malaysia
}

Background: Depression is a recognized complication of lung cancer underreported in developing countries such as Malaysia. Treating and identifying depression in cancer patients increases survival and quality of life. Our objectives are to study prevalence of depressive symptoms in newly diagnosed lung carcinoma, and examine the relationship of depressive symptoms with other influencing risk factors.

Methods: A 2-year, cross sectional study February 2015-February 2017, was conducted at Hospital Tengku Ampuan Afzan, and Penang General Hospital. One hundred and three patients with newly diagnosed, biopsy confirmed primary lung carcinoma were recruited. Self-rated patient's identification sheet, validated Center for Epidemiologic Studies Depression (CES-D), and Dukes University Religion Index score from three different main languages were used.

Results: Prevalence of current depressive symptoms (CES-D total score $\geq 16$ ) is $37.9 \%$. The result suggests prevalence of those at high risk of moderate to major depression, may need treatment. Multivariate analysis reveals those with good Eastern Cooperation Oncology Group factor $(\eta 2=0.24, \mathrm{p}<0.001)$ married $(\eta 2=0.14, \mathrm{p}<0.001)$ with intrinsic religiosity (IR) $(\eta 2=0.07, \mathrm{p}<0.02)$ are more resistant to depression.

Conclusion: One in three of lung carcinoma patients, are at increased risk for depression. Clinicians should be aware that risk is highest in those with poor performance status, single, and with poor IR. We suggest routine screening of depression symptoms as it is feasible, to be performed during a regular clinic visit with immediate referral to psychiatrist when indicated.

Keywords: Lung Neoplasms; Depressive Symptoms; Depression; Carcinoma; Prevalence; Risk Factors

\section{Address for correspondence: K. K. Shahedah, M.Med.}

Department of Internal Medicine, Kulliyyah of Medicine, International Islamic University Malaysia, Jalan Sultan Ahmad Shah, 25200 Kuantan, Pahang, Malaysia

Phone: 60-19-7484020, Fax: 60-9-5171897

E-mail: shahedah@iium.edu.my

Received: May. 28, 2018

Revised: Jul. 14, 2018

Accepted: Oct. 16, 2018

Published online: Dec. 20, 2018

(c) It is identical to the Creative Commons Attribution Non-Commercial License (http://creativecommons.org/licenses/by-nc/4.0/).

Copyright $\odot 2019$

The Korean Academy of Tuberculosis and Respiratory Diseases.

\section{Introduction}

Lung carcinoma is the third most common cancer as well as the most common cause of cancer deaths accounting for $19.8 \%$ of all medically certified, cancer related mortality in Malaysia. Globally, lung carcinoma occurred in approximately 1.8 million patients in 2012 and brought on an estimated 1.6 million numbers of deaths ${ }^{1}$. Unfortunately, $75 \%$ of patients with lung cancer tend to present at advanced stage that is not amenable to cure ${ }^{2}$. Despite advances in therapy, 5 -year survival rates average approximately $15 \%$ for all individuals with lung cancer.

With the uncertainty of the treatments outcomes, debilitating nature of cancer progression, and side effects of treatments 
given, cancer patients tend to encounter depression and other psychiatric illness more frequently compared to those with other diseases ${ }^{4}$. The prevalence of major depression was reported highest in patients with lung cancer (13.1\%), followed by gynecologic cancer (10.9\%), breast cancer (9.3\%), colorectal cancer $(7.0 \%)$, and genitourinary cancer (5.6\%), as shown in the study conducted by Walker et al. ${ }^{5}$ at several cancer clinics in Scotland. Different results were noted in another study done by Hopwood and Stephens ${ }^{6}$ over 526 inoperable lung cancer patients from Medical Research Council Lung Cancer, United Kingdom. From the study, depression was self-rated in $33 \%$ and shows increment up to $50 \%$ of patients over time before commencement of treatment ${ }^{6}$. While, western literature describes varying rates ( $11 \%-44 \%$ prevalence) of depression in lung cancer patients ${ }^{7}$, there has been a lack of Asian studies on the prevalence of depression especially in the developing countries.

A pilot study investigating the correlation of depression after the diagnosis of advanced non-small cell lung carcinoma and its effect on survival was carried out and it found that patients with depression had shorter median survival than those without depression ${ }^{8}$. Meta-analyses drawn from 76 studies (176,863 patients) confirms that the relative risk of mortality increases by $17 \%$ in cancer patients with depression when compared with those without depression ${ }^{9}$. Early palliative care addressing depression treatment in newly diagnosed lung carcinoma predicts survival benefit ${ }^{10}$. Psychotherapy and antidepressants have been found to increase the survival of cancer patients in three randomized studies reported by Spiegel compared to the control ${ }^{11}$.

Many studies conducted in cancer populations have use Center for Epidemiologic Studies Depression (CES-D) score as a tool to measure clinical depression symptoms. Instead of focusing on physical manifestation of depression that can overlap with cancer symptoms, CES-D score has the advantage of assessing cognitive and affective components of depression that's sensible for medically ill patients like the cancer population. A study done by Hann et al. ${ }^{12}$ in 1999 to measure validity and reliability of CES-D in breast cancer population, established CES-D score as a valid and reliable measure of depression symptoms in cancer patient. The CES-D is found to have good internal consistency, with alpha coefficients 0.85 for both groups, as well as adequate test-retest reliability in both of the groups. Construct validity is signified in two ways, via comparisons between the groups and by comparing the CES-D with measures of fatigue, anxiety, and global mental health functioning. This design is suitable for use in clinical psychosocial research with cancer patients ${ }^{13}$.

In our study, the depressive symptoms are assessed using the center of epidemiology scale. The prevalence of depression symptoms was measured using this score, with 16 was taken as the cut-off point of depressed level or probable depression.
Religious commitments have shown beneficial effect towards depression ${ }^{14}$. There is a growing body of evidence that religion can buffer depression and support healing process in medical illness ${ }^{15}$. American Psychiatric Association (APA) also suggests that it is useful for the clinician to get information about religious or ideological orientation of the patient, so we can address it in an appropriate way during the treatment ${ }^{16}$. However, only a few studies in Asia have focused on religious perspectives and its effect on depression as well as other positive outcome on mental well-being ${ }^{17}$.

Dukes University Religion Index (DUREL) score is used as a brief and comprehensive tool to measure religious commitment, in epidemiological studies to examine the relationship between religion and health outcomes. It consists of five items or questions that cover religion commitment that can either be used in a cross sectional study or longitudinal study. DUREL has been used worldwide in over hundred published studies and has been translated into 10 different languages ${ }^{18}$. In our study, the religiosity is assessed using the DUREL score. Three different versions of the score have been validated in English, Malay, and Chinese with acceptable Cochrane alpha and high internal consistency. Malay translated version of DUREL among nursing students in Malaysia demonstrated good parallel reliability (0.70), test-retest reliability (0.68) (Spearman's rho, $\mathrm{p}<0.01$ ) and fair internal consistency (Cronbach's alpha $=0.45)^{19}$. Chinese translated version of DUREL has a good reliability for college students. The internal consistency of scale Cronbach $\alpha$ of the DUREL Chinese version is 0.847 while Cronbach $\alpha$ of the Han and Hui ethnicities were 0.720 and 0.793 . The Internal consistency for total item is 0.890 and they are from 0.447 to 0.879 for the individual items ${ }^{20}$.

Our current understanding of the prevalence of depression in lung carcinoma in Malaysia is based on studies done over for the past 20 years are mainly from Western countries which emphasizes the need for local data. To our knowledge, this is the first study to systematically examine the prevalence of depression and its correlates among Malaysian diagnosed with lung cancer. The researcher aims to increase awareness among clinicians and identify those who are at higher risk. By detecting depression early, their quality of life and survival may improve with prompt treatment.

In this study, our objectives were (1) to study the prevalence of clinically significant depressive symptoms in newly diagnosed lung carcinoma as assessed by the CES-D (score $\geq 16 / 60$ ) and (2) to study the relationship of depressive symptoms severity in newly diagnosed lung carcinoma with other associated risk factors. 


\section{Materials and Methods}

This was a 2-year cross-sectional study carried out at Hospital Tengku Ampuan Afzan, Kuantan (HTAA), Pahang and Penang General Hospital from February 2015 to February 2017. Both of the hospitals are the only tertiary referral government hospital providing lung cancer treatment in Pahang and Penang, respectively. This study received the approval of the Ethics Committee of International Islamic University Malaysia (No. IIUM/305/14/11/2/IREC 418). All patients consented and are analysed in the study.

All consecutive patients who were suspected to have lung cancer from the medical and respiratory wards, respiratory clinic, and bronchoscopy suites, and who gave their informed consent were recruited. The definite diagnosis of primary lung cancer was based on histological or cytological examination. Only the newly diagnosed lung carcinoma within 2-8 weeks of date of histology or cytology confirmation was recruited. The inclusion criteria were all newly diagnosed lung cancer patients with age more than 21 years old, have capability to self-administered the questionnaires and able to understand and read Bahasa Melayu, English, or Chinese (Mandarin).

The patients with the diagnoses of lung secondaries, mesothelioma, inconclusive histological diagnosis were excluded from the survival analysis. Patients who had currently having psychiatric co-morbidity such as substance abuse disorders, psychotic disorders, anxiety disorders, or mental retardation and patients with a coexisting chronic debilitating illness such as end-stage renal disease, stroke, inflammatory bowel disease, epilepsy, preexisting mental illness (psychiatric illness), and malignancies other than lung carcinoma were also excluded from the study.

The patients' detailed demographic data including sex, race, marital status, number of children, education level, history of substance abuse or alcohol, history of psychiatry problem, smoking status, occupation, religion, cancer staging, status of brain metastasis, Eastern Cooperation Oncology Group (ECOG) performance status, and religiosity scale were recorded. Depression symptoms which were the outcome of the study were measured using CES-D and religiosity assessments as one of the influential risk of depressive symptoms is measured by DUREL score. In this study, religiosity refers to the patients' dedication towards organizational religious activities (ORA), non-organizational religious activities (NORA), and intrinsic religiosity (IR).

Marital status was classified in two categories of married or single (separated/divorced/widow) during the interview. History of alcohol intake was defined as those who previously have taken more than 21 unit of alcohol per week for men, and fourteen unit of alcohol per week for women. History of taking substance abuse was defined as those who actively taking the substances currently or in the past. Cancer staging was based on the Classification of Malignant Tumors (TNM) staging of primary lung carcinoma. Metastasis defined as presence of computed tomography brain evidence of metastasis to brain. The performance status of the patients at presentation was classified according to the ECOG.

The CES-D is utilized as a tool of quantifying depression. CES-D score of $\geq 16 / 60$ means clinically significant depression or moderate to severe depressive symptoms which may need treatment which is taken as the cutoff point to measure prevalence of clinically significant depression in this study. The 20-item CES-D scale measures depressive symptoms experienced for the past whole week prior to its administration. Each items are scored on a four-point scale, with a total score ranging from 0 to 60 . A higher score is indicative of more depressive symptoms. At the cut-off 16 , sensitivity was 0.87 (95\% confidence interval [CI], 0.82-0.92), specificity 0.70 (95\% CI, 0.65-0.75), and diagnostic odds ratio 16.2 (95\% CI, 10.49-25.10) ${ }^{7}$. Three different versions of the score managed a high Cochrane alpha and high internal consistency upon validation in all three languages: English, Malay, and Chinese.

In the event that any subject is found to have scored high levels of depressive symptoms $>16$, the clinician will be notified to facilitate referral to a psychiatrist.

DUREL score is used to measure religious commitment of the respondent. It consists of five items (questions) with three subscales which include ORA, NORA, and IR which assesses the three major dimensions of religious commitment. The organizational item asked about frequency of attendance at religious services (six response options: 1, never; 6, more than one time per week) score $0-6$. The non-organizational item measure about frequency of private religious activities such as prayer or meditation (six response options: 1 , rarely or never; 6 , more than one time per day) score $0-6$. The three last questions, or IR items asked about ever experiencing the presence of the divine, allowing religious beliefs to guide an approach to life, and transporting religion into other areas of life which score $0-15$ (five response options: 1 , definitely not true; 5 , definitely true $)^{18}$. The higher the scale measured in each separate subscale referring to the more religious were the individual according to the separate dimensions of ORA, NORA, and IR.

Analysis was performed using IBM SPSS Statistics for windows version 23 (IBM Corp., Armonk, NY, USA). Descriptive analyses were performed for all recruited cases detected during the study period. Tables were generated to summarize prevalence, epidemiology and outcome. CES-D score and DUREL score (IR, ORA, and NORA) were described using mean and SD. The prevalence of depressive symptoms is presented in count and percentage. Multivariate analysis using General Linear Model (univariate analysis of covariance) ANCOVA was used to study the relationship between the depression symptoms (CES-D score) and associated risk factors. p-values of $<0.05$ were considered statistically significant. 


\section{Results}

A total 103 patients from ward and outpatient clinic of Hospital Tengku Ampuan Afzan, and Penang General Hospital from February 2015 to February 2017 are eligible and enrolled in the study.

\section{Sociodemographic characteristics}

Demographic characteristics of the respondents are summarized in Table 1. The age of the participants in this study ranged from 21 to 83 years (mean \pm standard deviation, $60.5 \pm 10.3$ years) and large proportion of the respondents

Table 1. Sociodemographic of respondents $(n=103)$

\begin{tabular}{|lc|}
\hline \multicolumn{1}{|c|}{ Variable } & Value \\
\hline Age group, yr & $5(4.9)$ \\
\hline$<41$ & $9(8.7)$ \\
\hline $41-50$ & $34(33.0)$ \\
\hline $51-60$ & $38(36.9)$ \\
\hline $61-70$ & $17(16.5)$ \\
\hline$>71$ & \\
\hline Sex & $72(69.9)$ \\
\hline Male & $31(30.1)$ \\
\hline Female & \\
\hline Race & $63(61.2)$ \\
\hline Malay & $33(32.0)$ \\
\hline Chinese & $3(2.9)$ \\
\hline Indian & $4(3.9)$ \\
\hline Others & \\
\hline Marital status & $92(89.3)$ \\
\hline Married or partnered & $4(3.9)$ \\
\hline Single & $2(1.9)$ \\
\hline Divorced & $5(4.9)$ \\
\hline Widow & \\
\hline Education level & $7(6.8)$ \\
\hline No formal education & $49(47.6)$ \\
\hline Primary & $44(42.7)$ \\
\hline Secondary & $3(2.9)$ \\
\hline Tertiary & \\
\hline No. of children & $5(7.8)$ \\
\hline No children & $73(70.9)$ \\
\hline 1 & \\
\hline 2 & \\
\hline$>2$ & \\
\hline & \\
\hline
\end{tabular}

(53\%) are 61 years or older. The study population is predominantly male $(69.9 \%, \mathrm{n}=72)$, Malay $(69.9 \%)$ and Muslim (62.1\%). A large proportion of the respondents (89.3\%) are married or having a partner and $71 \%$ of them have three or more children. In terms of educational background, most of the of the respondents $(47.6 \%)$ have attended up to either primary school or secondary school education (42.7\%), while only $6.8 \%$ of participant did not enter school. Majority of the respondents (62\%) are employed. Out of this, most of them are primarily from non-professional worker group (51.5\%), mainly self-employed.

\section{Lifestyle characteristic of the responder}

Table 2 shows the lifestyle characteristic of the respondents. Majority of the respondents (62.1\%) have history of smoking in the past. One participant (1.0\%) had history of substance abuse, however was not actively taking any substance for the past 2 years prior to the study. None of the respondents consume alcohol excessively as defined by substance abuse mental health service administration and denied history of alcohol dependency; none had history of psychiatric problem. Among those taking alcohol (9.7\%), all of participants (100\%) are social drinker.

\section{Clinical characteristics of the responder}

Majority of the patients (62\%) presented at advanced stage of stage IV cancer, and most of the respondents (65\%) have

Table 1. Continued

\begin{tabular}{|lc|}
\hline \multicolumn{1}{|c|}{ Variable } & Value \\
\hline Religion & $63(61.2)$ \\
\hline Islam & $4(3.9)$ \\
\hline Christian & $26(25.2)$ \\
\hline Buddhist & $5(4.9)$ \\
\hline Chinese religion & $2(1.9)$ \\
\hline Hindu & $3(2.9)$ \\
\hline Others & \\
\hline Employment status & $9(8.7)$ \\
\hline Professional & $53(51.5)$ \\
Non-professional & $41(39.8)$ \\
\hline Unemployed & \\
Religiosity & $3.3 \pm 1.4$ \\
\hline ORA score & $2.4 \pm 1.6$ \\
\hline NORA score & $10.3 \pm 2.6$ \\
\hline IR score & $16.0 \pm 4.9$ \\
\hline DUREL score & \\
\hline
\end{tabular}

Values are presented as number (\%) or mean \pm standard deviation. 
Table 2. Lifestyle characteristics of respondents $(n=103)$

\begin{tabular}{|lc|}
\hline \multicolumn{1}{|c|}{ Variable } & No. (\%) \\
\hline Family history of psychiatric illness & $0(0)$ \\
\hline Yes & $1(1.0)$ \\
\hline History of substance abuse & \\
\hline Yes (opiates) & $64(62.1)$ \\
\hline Smoking status & \\
\hline Yes & $10(9.7)$ \\
\hline History of taking alcohol & $0(0)$ \\
\hline Yes & $10(100)$ \\
\hline Alcohol abuse/dependence & $1(10.0)$ \\
\hline Social drinker & $9(90.0)$ \\
\hline Type of alcohol intake (n=10) & $55(53.4)$ \\
\hline Beer/Lager/Cider/Shandy & $9(16.3)$ \\
\hline Others & $29(52.7)$ \\
\hline Medical comorbidity & $7(12.7)$ \\
\hline Diabetes mellitus & $10(18.0)$ \\
\hline Hypertension & \\
\hline Diabetes mellitus and hypertension & \\
\hline Others & \\
\hline
\end{tabular}

histopathology of adenocarcinoma. Large proportion of participants (61.2\%) are at ECOG 1 at diagnosis, with only $1.0 \%$ of participants present at ECOG 4 (Table 3). Twelve point six percent of patients $(n=13)$ have evidence of metastasis to brain; however, they were still included in the study as they had full understanding of the study objective, were able to give consent, understand and able to complete the self-reported questionnaires in the respected languages without alteration in mental status as clinically examined by researcher during the interview, as included in inclusion criteria ${ }^{21}$.

4. Prevalence of clinically significant depressive symptoms in newly diagnosed lung carcinoma

In this present study, we found the prevalence of current depressive symptoms (CES-D total score $\geq 16$ ) is $37.9 \%$ as shown in Figure 1. In comparing between two centres, Hospital Tengku Ampuan Afzan ( $\mathrm{n}=74)$ demonstrated prevalence of $27.5 \%$ while Penang General Hospital (n=29) was $14.0 \%$.

5. Relationship between risk factors and depressive symptoms severity

Multivariate analysis confirms that marital status $(\eta 2=0.14$, $p<0.001)$, ECOG factor $(\eta 2=0.24, p<0.001)$, and IR $(\eta 2=0.07$, $\mathrm{p}<0.02$ ) are independently associated with depression symptom score. Those married or having a partner have lower
Table 3. Clinical characteristics of lung cancer $(n=103)$

\begin{tabular}{|c|c|}
\hline Variable & Value \\
\hline \multicolumn{2}{|l|}{ Tissue histopathology } \\
\hline Adenocarcinoma & $67(65.0)$ \\
\hline Squamous cell carcinoma & $26(25.2)$ \\
\hline Large cell carcinoma & $1(1.0)$ \\
\hline Adenosquamous carcinoma & $2(1.9)$ \\
\hline Small cell carcinoma & $7(6.8)$ \\
\hline \multicolumn{2}{|l|}{ Stage of lung cancer at diagnosis } \\
\hline 1 & $1(1.0)$ \\
\hline 2 & $2(1.9)$ \\
\hline 3 & $31(30.1)$ \\
\hline 4 & $69(67.0)$ \\
\hline \multicolumn{2}{|l|}{ Metastasis } \\
\hline Yes & $13(12.6)$ \\
\hline \multicolumn{2}{|l|}{ Marital status } \\
\hline Married or partnered & $92(89.3)$ \\
\hline Single & $4(3.9)$ \\
\hline Divorced & $2(1.9)$ \\
\hline Widow & $5(4.9)$ \\
\hline \multicolumn{2}{|l|}{ ECOG status } \\
\hline 0 & $6(5.8)$ \\
\hline 1 & $63(61.2)$ \\
\hline 2 & $20(19.4)$ \\
\hline 3 & $13(12.6)$ \\
\hline 4 & $1(1.0)$ \\
\hline \multicolumn{2}{|l|}{ No. of children } \\
\hline No children & $8(7.8)$ \\
\hline 1 & $5(4.9)$ \\
\hline 2 & $17(16.5)$ \\
\hline$>2$ & $73(70.9)$ \\
\hline CES-D score & $14.0 \pm 6.5$ \\
\hline Low $(<16)$ & $64(62.1)$ \\
\hline $\operatorname{High}(\geq 16)$ & $39(37.9)$ \\
\hline
\end{tabular}

Values are presented as number (\%) or mean \pm standard deviation. CES-D: Center for Epidemiologic Studies Depression.

mean of depression score by 9.42 compared to being single/ widow/never married/divorcee. ECOG 0 and 1 have lower mean depression score compared to ECOG 4 by 27.13 and 23.86 , respectively. IR reduces depression score by 0.93 as shown in Table 4. 
Pie chart: Prevalence of depression symptoms in newly diagnosed lung carcinoma

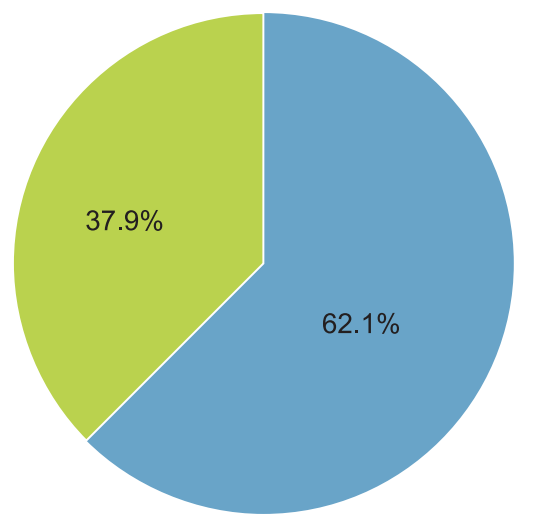

Figure 1. Prevalence of depressive symptoms in newly diagnosed lung carcinoma. CES-D: Center for Epidemiologic Studies Depression.

\section{Discussion}

\section{Prevalence of depression symptoms in newly diag-} nosed lung carcinoma

Our local study showed the overall prevalence of depressive symptoms among pre-treated newly diagnosed lung carcinoma over period of 2 years (February 2015-February 2017), was moderately high at $37.9 \%$. There was considerable variability among prevalence of depression symptoms obtained from other Asian countries like China ranging from $38 \%$ to $46.1 \%$, India with $28 \%$, and Thailand with $14.4 \%^{22-25}$. The sitespecific variation in prevalence, may reflect varying methods and self-reported instruments used to assess depression, differences in the patient population studied and exposure to chemotherapy. For instance, while the study in China used the Hospital Anxiety Depression Score (HADS) score to diagnose depressive symptoms, the Indian study used the Hamilton depression rating scale for similar objectives among pre-treated group of lung cancer. Another potential explanation for the moderately high rate of depression in our sample is that our sample included only pre-treated group of newly diagnosed lung carcinoma as depression symptoms were identified to be more common at the time of cancer diagnosis and predicted to persist during treatment ${ }^{26}$. At time of diagnosis some patients suffered increasing worriedness as initial reaction with greater tendency towards depression ${ }^{27}$ supported by Chen et $\mathrm{al}^{25}$ with similar findings. Presently, limited studies have been done in Asian to explore the pre-treatment prevalence of depression in lung cancer.

Our findings were also compatible with a western study done by Hopwood and Stephens ${ }^{6}$, which stated that in lung cancer patients, the prevalence of self-reported depression was approximately $33 \%$. This differed from a pooled prevalence of depression in lung cancer from a meta-analysis of western countries describing varying rates ranging from $11 \%$ to $44 \%$, generally due to variations in methodological approaches to the dimension of depression, and variety on the cancer populations studied ${ }^{28}$.

With regards to the use of the CES-D score as main instrument of assessing depressive symptoms, our findings are similar to that of the national cohort assessment from National Cancer Institute-funded Cancer Care Outcomes Research and Surveillance (CanCORS) Consortium, a prospective, observational, national study of practices and outcomes for patients with newly diagnosed lung involving 1,790 patients by Sullivan et al. ${ }^{29}$ which used the same method with a prevalence rate of $37.8 \%$. We believe that the prevalence reported in this study is more representative of the true burden of depressive symptoms among newly diagnosed lung carcinoma patients in Malaysia.

Self-report instruments such as the CES-D score were designed as tools to assess the severity of depression rather than as a diagnostic tool for major depressive disorders. The use of these tools may overestimate the presence of depression but is useful to detect early signs of a depressive illness or emotional distress which warrants treatment. On the other hand, assessments with diagnostic interviews in patients with depressive symptoms may underestimate need for psychological and social support and clinicians may have inadequate skills and knowledge to detect these problems. This in turn would lead to under treatment and would put the patient at risk of developing full blown depression. Standardized diagnostic tests are also time consuming and labour intensive which limits its use especially in a busy clinic setting. Several studies have advocated the use of reliable self-report instruments such as the HADS-D, the CES-D or the beck depression inventory which would eliminate the need for specific skills and allow early detection and subsequent referral for specialised psychosocial $\operatorname{care}^{30}$. The patient would be able to be referred to a specialized psychological care provide should there be an increased risk of depression detected ${ }^{31}$. In our study, those patients with CES-D score of equal or more than 16 were referred to psychiatry for further assessment and follow up.

\section{Influencing risk factors of developing depression in lung carcinoma}

From the present study, we identified three influencing factors of depressive symptoms in newly diagnosed lung carcinoma, which were poor ECOG factor, those who are unmarried or not having partner and those with IR. Our data confirms that ECOG factor was substantially the most important risk factor with (partial eta squared $=0.24, p<0.001$ ), while IR had the weakest correlation towards depression symptoms with (partial eta square $=0.07, \mathrm{p}<0.02$ ). Other factors such as 
Table 4. Risk factors for depression symptoms severity

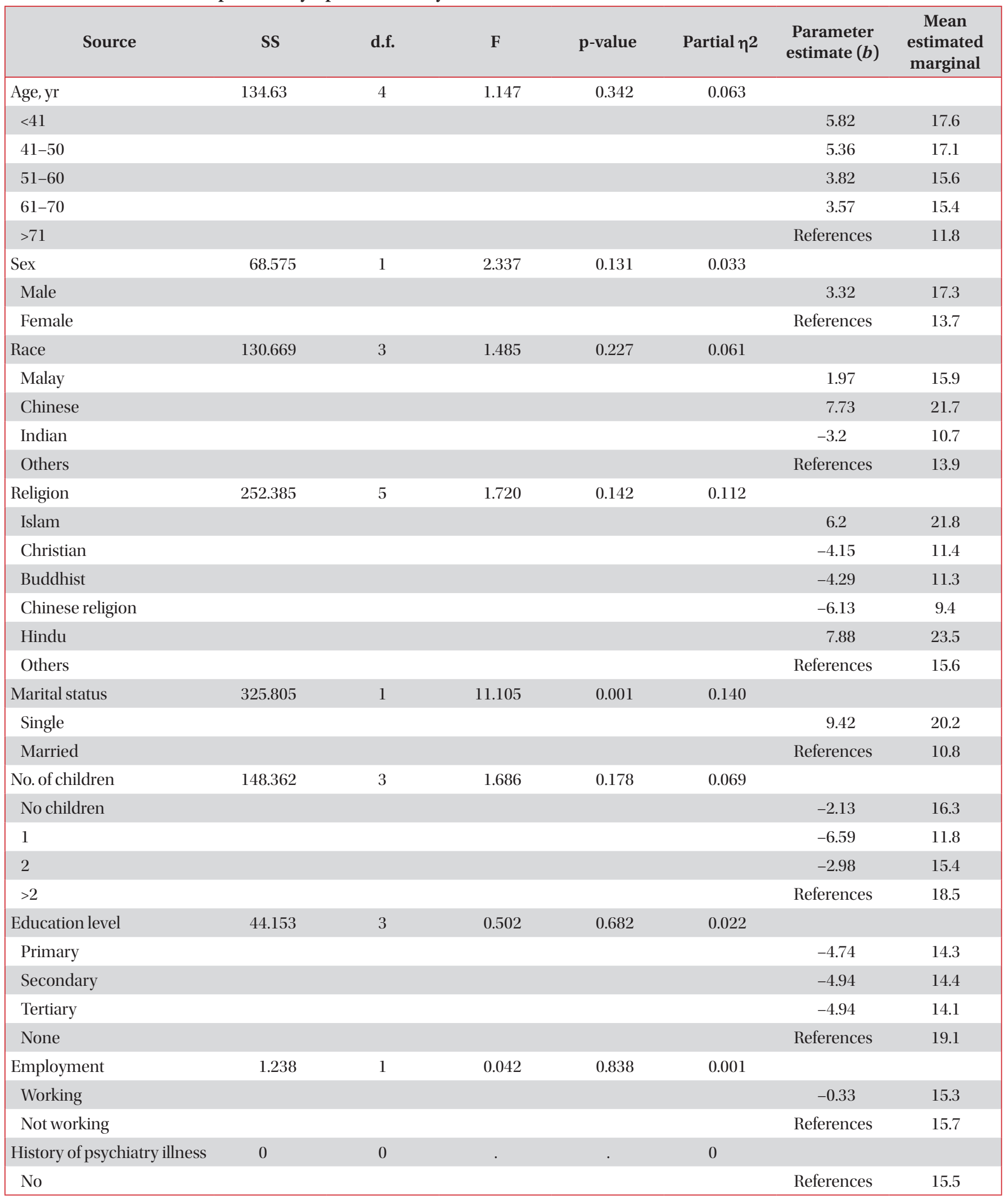


Table 4. Continued

\begin{tabular}{|c|c|c|c|c|c|c|c|}
\hline Source & SS & d.f. & $\mathbf{F}$ & p-value & Partial $\eta^{2}$ & $\begin{array}{l}\text { Parameter } \\
\text { estimate }(b)\end{array}$ & $\begin{array}{c}\text { Mean } \\
\text { estimated } \\
\text { marginal }\end{array}$ \\
\hline Family history & 0 & 0 & . & . & 0 & & \\
\hline \multicolumn{8}{|l|}{ Psychiatric illness } \\
\hline No & & & & & & References & 15.5 \\
\hline Smoking status & 0.293 & 1 & 0.010 & 0.921 & 0 & & \\
\hline No & & & & & & 0.211 & 15.6 \\
\hline Yes & & & & & & References & 15.4 \\
\hline $\begin{array}{l}\text { History of substance abuse/ } \\
\text { alcoholic abuse }\end{array}$ & 11.128 & 1 & 0.379 & 0.540 & 0.006 & & \\
\hline No & & & & & & -3.93 & 13.5 \\
\hline Yes & & & & & & References & 17.5 \\
\hline Cancer staging & 88.64 & 3 & 1.007 & 0.395 & 0.043 & & \\
\hline Stage I & & & & & & -4.27 & 13.7 \\
\hline Stage II & & & & & & -6.35 & 11.6 \\
\hline Stage III & & & & & & 0.74 & 18.7 \\
\hline Stage IV & & & & & & References & 18.0 \\
\hline Metastasis status & 11.04 & 1 & 0.376 & 0.542 & 0.006 & & \\
\hline No & & & & & & 1.22 & 16.1 \\
\hline Yes & & & & & & References & 14.9 \\
\hline ECOG factor & 615.68 & 4 & 5.246 & 0.001 & 0.236 & & \\
\hline 0 & & & & & & -27.1 & 6 \\
\hline 1 & & & & & & -23.8 & 9.3 \\
\hline 2 & & & & & & -10.5 & 14.6 \\
\hline 3 & & & & & & -10.5 & 14.5 \\
\hline 4 & & & & & & References & 33.1 \\
\hline ORA & 1.066 & 1 & 0.036 & 0.849 & 0.001 & -0.15 & - \\
\hline NORA & 5.267 & 1 & 0.180 & 0.673 & 0.003 & -0.23 & - \\
\hline IR & 159.783 & 1 & 5.446 & 0.023 & 0.074 & -0.93 & - \\
\hline Error & 24,598 & 103 & & & & & \\
\hline Corrected total & $4,353.96$ & 102 & & & & & \\
\hline
\end{tabular}

Depressive symptom severity=total score on the Center for Epidemiologic Studies Depression.

$\mathrm{R}^{2}=0.542$ (adjusted $\left.\mathrm{R}^{2}=0.313\right)$.

${ }^{*} \mathrm{p}<0.05$.

SS: sum of squares; ECOG: Eastern Cooperation Oncology Group; ORA: organizational religious activities; NORA: non-organizational religious activities; IR: intrinsic religiosity.

age, sex, races, religion, number of children, education level, employment status, smoking status, history of substances or alcoholic abuse, cancer staging, metastasis status, were found to be non-significant. It also suggests that religiosity measured by NORA and ORA were found to have no correlation. We noted some limitation in our study to measure risk in those who have history of psychiatric illness or in present having ac- tive illness in the present as we do not have enough power as a result of not enough sample size to represent those with the background factor.

In accordance with other studies in advanced cancer patients, these findings also do not support the common assumption that the increased risk of depression is associated with advanced age and the female gender ${ }^{32}$. Kader Maideen et 
$\mathrm{al}^{33}$ in assessing predictor of depression in 1,556 adult population, found the Chinese to be at greater risk of depression compared to the Malays. We found that our mean depression score was higher in the Chinese group, which warrants a larger sample population to be recruited to show significant result $^{33}$. Advanced stage of the disease is known to increase the risk of depression in a multivariate analysis by Rosentein ${ }^{34}$. This is consistent with trends of depression score in our study. Again it is not significant due to the effect of a small sample size.

Having IR is shown to reduce depressive symptoms. Our findings are comparable with a review of 80 published literatures of association of depressive risk and religiosity who achieved the same conclusion of positive effect of IR towards reducing depression ${ }^{35}$.

\section{Clinical implication of the findings}

As a high prevalence of depression in lung cancer patients was demonstrated in this study, it is important that all patients be screened for depression, with more attention given to those with poor ECOG factor, being single and low intrinsic religiosity. Depression confers a small mortality risk and predicts poorer lung function outcomes among lung cancer patients. This will in turn translate to higher costs of medical treatment, worsening of both physical and psychiatric symptoms and difficulty of self-care and adherence to treatment. Depression would also interfere with patient's cognitive abilities which would hamper their ability to understand explanations and recommendations given by their healthcare provider. Depression is treatable and therefore it is important to recognise symptoms early to allow prompt referral and management.

The likelihood of depressed patients to be non-compliant to treatment is triple compared to their non-depressed counterparts. It is therefore important to understand causes and to explore the mechanisms related to the matter through future research $^{36}$.

\section{Conclusion and recommendation}

Depression is common in lung cancer patients, especially in those with functional limitations (poor ECOG factor), being single and reduced aspect of religiosity (IR). Routine screening and prevention of depression are warranted among lung cancer patients and appropriate intervention is an essential part of lung cancer therapy. There is a need to establish clinical programs and research in psycho-oncology, especially in our country as little emphasis is put on the importance of addressing the psychiatric aspect of the disease. A comprehensive psycho-oncology service is recommended, especially in cancer care centres.

The CES-D score is widely applied in the cancer field, but it is acknowledged that the prevalence of mood disorder based on self-report questionnaires must be carefully interpreted within the limits of the accuracy of such scales, as it should be further assessed with the diagnostic and statistical manual of mental disorders IV criteria which is the gold standard diagnostic tool. This study brings to note an important clinical issue which is the need for consultation with liaison psychiatry to guide decisions in diagnosis and management.

\section{Authors' Contributions}

Conceptualization: Shahedah KK, How SH, Kuan YC. Methodology: Shahedah KK, How SH, Mohd Faiz MT. Formal analysis: Shahedah KK, Jamalludin AR. Data curation: How SH. Software: Jamalludin AR. Data collection: Shahedah KK, Ong CK. Writing - original draft preparation: Shahedah KK. Writing - review and editing: How SH, Mohd Faiz MT, Jamalludin AR. Approval of final manuscript: all authors.

\section{Conflicts of Interest}

No potential conflict of interest relevant to this article was reported.

\section{Acknowledgments}

We are grateful to all respiratory staffs at Hospital Tengku Ampuan Afzan (HTAA), Kuantan, Kulliyyah of Medicine, IIUM and Penang General Hospital for their assistance.

\section{References}

1. Torre LA, Bray F, Siegel RL, Ferlay J, Lortet-Tieulent J, Jemal A. Global cancer statistics, 2012. CA Cancer J Clin 2015;65:87108.

2. Molina JR, Adjei AA, Jett JR. Advances in chemotherapy of non-small cell lung cancer. Chest 2006;130:1211-9.

3. Siegel RL, Miller KD, Jemal A. Cancer statistics, 2015. CA Cancer J Clin 2015;65:5-29.

4. Spiegel D. Cancer and depression. Br J Psychiatry Suppl 1996;(30):109-16.

5. Walker J, Cassidy J, Sharpe M; SMaRT Oncology-3 Trialists. The third symptom management research trial in oncology (SMaRT oncology-3): a randomised trial to determine the efficacy of adding a complex intervention for major depressive disorder (depression care for people with lung cancer) to usual care, compared to usual care alone in patients with lung cancer. Trials 2009;10:92.

6. Hopwood P, Stephens RJ. Depression in patients with lung cancer: prevalence and risk factors derived from quality-of- 
life data. J Clin Oncol 2000;18:893-903.

7. Vilagut G, Forero CG, Barbaglia G, Alonso J. Screening for depression in the general population with the center for Epidemiologic Studies Depression (CES-D): a systematic review with meta-analysis. PLoS One 2016;11:e0155431.

8. Montazeri A, Gillis CR, McEwen J. Quality of life in patients with lung cancer: a review of literature from 1970 to 1995. Chest 1998;113:467-81.

9. Pinquart M, Duberstein PR. Depression and cancer mortality: a meta-analysis. Psychol Med 2010;40:1797-810.

10. Pirl WF, Greer JA, Traeger L, Jackson V, Lennes IT, Gallagher ER, et al. Depression and survival in metastatic non-smallcell lung cancer: effects of early palliative care. J Clin Oncol 2012;30:1310-5.

11. Spiegel D, Bloom JR, Kraemer HC, Gottheil E. Effect of psychosocial treatment on survival of patients with metastatic breast cancer. Lancet 1989;2:888-91.

12. Hann D, Winter K, Jacobsen P. Measurement of depressive symptoms in cancer patients: evaluation of the Center for Epidemiological Studies Depression Scale (CES-D). J Psychosom Res 1999;46:437-43.

13. Pirl WF, Temel JS, Billings A, Dahlin C, Jackson V, Prigerson HG, et al. Depression after diagnosis of advanced non-small cell lung cancer and survival: a pilot study. Psychosomatics 2008;49:218-24.

14. Koenig HG. Research on religion, spirituality, and mental health: a review. Can J Psychiatry 2009;54:283-91.

15. Koenig HG, Hays JC, George LK, Blazer DG, Larson DB, Landerman LR. Modeling the cross-sectional relationships between religion, physical health, social support, and depressive symptoms. Am J Geriatr Psychiatry 1997;5:131-44.

16. American Psychiatric Association. Guidelines regarding possible conflict between psychiatrists' religious commitment and psychiatric practice. Am J Psychiatry 1990;147:542.

17. Ginsburg ML, Quirt C, Ginsburg AD, MacKillop WJ. Psychiatric illness and psychosocial concerns of patients with newly diagnosed lung cancer. CMAJ 1995;152:701-8.

18. Koenig HG, Bussing A. The Duke University Religion Index (DUREL): a five-item measure for use in epidemological studies. Religions 2010;1:78-85.

19. Nurasikin MS, Aini A, Aida Syarinaz AA, Ng CG. Validity and reliability of the Malay version of Duke University Religion Index (DUREL-M) among a group of nursing student. Malays J Psychiatr 2010;19:MJP-02-12-10.

20. Wang J, Sun YL, Rong Y, Zhang YH, Wang ZZ. The reliability of Chinese version DUREL scale. J Ningxia Med Univ 2013;35:550-2.

21. Rodin D, Banihashemi B, Wang L, Lau A, Harris S, Levin W, et al. The Brain Metastases Symptom Checklist as a novel tool for symptom measurement in patients with brain metastases undergoing whole-brain radiotherapy. Curr Oncol 2016;23:e239-47.
22. Shi Y, Gu F, Hou LL, Hu YQ. Self-reported depression among patients with non-small cell lung cancer. Thorac Cancer 2015;6:334-7.

23. Abhishekh HA, Balaji AL, Mehta RM. Depression in lung cancer patients. Indian J Psychiatry 2014;56:307.

24. Maneeton B, Maneeton N, Reungyos J, Intaprasert S, Leelarphat S, Thongprasert S. Prevalence and relationship between major depressive disorder and lung cancer: a cross-sectional study. Onco Targets Ther 2014;7:815-21.

25. Chen J, Li W, Cui L, Qian Y, Zhu Y, Gu H, et al. Chemotherapeutic response and prognosis among lung cancer patients with and without depression. J Cancer 2015;6:1121-9.

26. Sullivan DR, Forsberg CW, Ganzini L, Au DH, Gould MK, Provenzale D, et al. Longitudinal changes in depression symptoms and survival among patients with lung cancer: a national cohort assessment. J Clin Oncol 2016;34:3984-91.

27. Montazeri A, Milroy R, Hole D, McEwen J, Gillis CR. Anxiety and depression in patients with lung cancer before and after diagnosis: findings from a population in Glasgow, Scotland. J Epidemiol Community Health 1998;52:203-4.

28. Massie MJ. Prevalence of depression in patients with cancer. In: NIH State-of-the-Science Conference on Symptom Management in Cancer: Pain, Depression, and Fatigue; 2002 Jul 15-17; Bethesda, MD, USA.

29. Sullivan DR, Forsberg CW, Ganzini L, Au DH, Gould MK, Provenzale D, et al. Depression symptom trends and health domains among lung cancer patients in the CanCORS study. Lung Cancer 2016;100:102-9.

30. Vodermaier A, Linden W, Siu C. Screening for emotional distress in cancer patients: a systematic review of assessment instruments. J Natl Cancer Inst 2009;101:1464-88.

31. Krebber AM, Buffart LM, Kleijn G, Riepma IC, de Bree R, Leemans CR, et al. Prevalence of depression in cancer patients: a meta-analysis of diagnostic interviews and self-report instruments. Psychooncology 2014;23:121-30.

32. Mystakidou K, Tsilika E, Parpa E, Katsouda E, Galanos A, Vlahos L. Assessment of anxiety and depression in advanced cancer patients and their relationship with quality of life. Qual Life Res 2005;14:1825-33.

33. Kader Maideen SF, Sidik SM, Rampal L, Mukhtar F. Prevalence, associated factors and predictors of depression among adults in the community of Selangor, Malaysia. PLoS One 2014;9:e95395

34. Rosenstein DL. Depression and end-of-life care for patients with cancer. Dialogues Clin Neurosci 2011;13:101-8.

35. McCullough ME, Larson DB. Religion and depression: a review of the literature. Twin Res 1999;2:126-36.

36. DiMatteo MR, Lepper HS, Croghan TW. Depression is a risk factor for noncompliance with medical treatment: metaanalysis of the effects of anxiety and depression on patient adherence. Arch Intern Med 2000;160:2101-7. 